\title{
Labisia pumila Upregulates Peroxisome Proliferator-Activated Receptor Gamma Expression in Rat Adipose Tissues and 3T3-L1 Adipocytes
}

\author{
Fazliana Mansor, ${ }^{1}$ Harvest F. Gu, ${ }^{2}$ Claes-Göran Östenson, ${ }^{2}$ Louise Mannerås-Holm, ${ }^{3}$ \\ Elisabet Stener-Victorin, ${ }^{3}$ and Wan Nazaimoon Wan Mohamud ${ }^{1}$ \\ ${ }^{1}$ Cardiovascular, Diabetes and Nutrition Research Centre, Institute for Medical Research, \\ 50588 Jalan Pahang, Kuala Lumpur, Malaysia \\ ${ }^{2}$ Department of Molecular Medicine and Surgery, Karolinska Institute, 17176 Stockholm, Sweden \\ ${ }^{3}$ Department of Physiology, Institute of Neuroscience and Physiology, University of Gothenburg, \\ Sahlgrenska Academy, 40530 Gothenburg, Sweden
}

Correspondence should be addressed to Fazliana Mansor; fazliana@imr.gov.my

Received 25 April 2013; Accepted 18 June 2013

Academic Editor: Neal Davies

Copyright ( 2013 Fazliana Mansor et al. This is an open access article distributed under the Creative Commons Attribution License, which permits unrestricted use, distribution, and reproduction in any medium, provided the original work is properly cited.

\begin{abstract}
Peroxisome proliferator-activated receptor gamma (PPARgamma) is a ligand-activated transcription factor that regulates lipid and glucose metabolism. We investigated the effects of Labisia pumila (LP) standardized water extract on PPARgamma transcriptional activity in adipocytes in vitro and in vivo. We used a rat model of dihydrotestosterone- (DHT-) induced polycystic ovary syndrome (PCOS), a condition characterized by insulin resistance. At 9 weeks of age, the PCOS rats were randomly subdivided into two groups: PCOS-LP $(50 \mathrm{mg} / \mathrm{kg} /$ day of LP) and PCOS-control ( $1 \mathrm{~mL}$ of deionised water) for 4-5 weeks on the same schedule. Realtime RT-PCR was performed to determine the PPARgamma mRNA levels. LP upregulated PPARgamma mRNA level by $40 \%$ in the PCOS rats. Western blot analysis further demonstrated the increased PPARgamma protein levels in parallel with upregulation in mRNA. These observations were further proven by adipocytes culture. Differentiated 3T3-L1 adipocytes were treated with final concentration of $100 \mu \mathrm{g} / \mathrm{mL} \mathrm{LP}$ and compared to untreated control and $10 \mu \mathrm{M}$ of rosiglitazone (in type of thiazolidinediones). LP increased PPARgamma expressions at both mRNA and protein levels and enhanced the effect of glucose uptake in the insulinresistant cells. The data suggest that LP may ameliorate insulin resistance in adipocytes via the upregulation of PPARgamma pathway.
\end{abstract}

\section{Introduction}

Labisia pumila var. alata (LP) (family, Myrsinaceae) or its local name, Kacip Fatimah, is a herbal plant with long history of being used as traditional medicine by Asian women especially those from the Malay Archipelago [1]. The plant grows in lowland primary forest at shady places or in secondary forests on humus-rich soils [2]. The water decoction is traditionally consumed to maintain women's pre- and postpartum health $[1,3]$. Components identified in LP extracts include flavonoids, ascorbicacid, beta-carotene, anthocyanin, phenols, and total saponins $[4,5]$.
Insulin resistance is characterized by a decrease in the uptake of glucose, especially by insulin target tissues, including adipose tissue and skeletal muscle [6]. Instead of merely being a storage depot, adipose tissue is now recognized as an important regulator of energy homeostasis [7] and a central player in the development of insulin resistance $[8,9]$. One key factor in supporting the central role of adipose tissue in whole-body glucose metabolism is peroxisome proliferatoractivated receptor gamma (PPARgamma), a nuclear receptor that is critical both for adipocyte differentiation and for maintenance of mature adipocytes. PPARgamma has the highest expression levels in adipose tissue compared with 
other metabolic organs, such as skeletal muscle, liver, and pancreas. It can be activated by synthetic compounds, including thiazolidinediones (TZDs) which are used clinically as insulin-sensitizing drugs and antidiabetic agents $[10,11]$. A representative of $\mathrm{TZD}$, rosiglitazone, is a potent agonist of PPARgamma and improves the differentiation of 3T3-L1 cells into adipocytes $[12,13]$. Treatment with PPARgamma agonists ameliorates insulin sensitivity along with the increase in the plasma adiponectin levels in rodents and human subjects, which at least in part contributes to its ameliorative effect on insulin resistance [14-16]. Some dietary compounds such as dietary lipids, isoflavones, and other flavonoids bind and transactivate PPARgamma [17].

Polycystic ovary syndrome (PCOS) is one of the most common endocrine and metabolic disorders, affecting approximately $5-10 \%$ of women in reproductive age. It is a complex endocrine and metabolic disorder associated with ovulatory dysfunction, hyperandrogenism, polycystic ovaries, insulin resistance, abdominal fat, and obesity [18-22]. In this study we determine the effects of LP on PPARgamma expressions in the adipose tissues of DHT-induced PCOS rats and glucose uptake in 3T3-L1 adipocytes.

\section{Materials and Methods}

2.1. Preparation of Standardized Labisia pumila Aqueous Extract. Preparation of aqueous LP extract was as described earlier [23]. The plant materials were obtained from central Peninsular Malaysia and a voucher specimen (FRI54816) was deposited at the Herbarium of FRIM. The standardized LPva aqueous extract was produced by a certified Good Manufacturing Practices herbal manufacturing facility using the method described in patent document number US 7879368 B2 [24]. The marker compound used was 3,4,5trihydroxybenzoic acid and typical yield was between 4 and $5 \%$. The leaves of LP were first oven-dried at $40^{\circ} \mathrm{C}$ for 3 days. Briefly, the method involved slow heating of the dried leaves in water at $80^{\circ} \mathrm{C}$ over a period of $3 \mathrm{~h}$, with continuous stirring. This extraction was repeated with an equal volume of fresh water, that is, a two-stage process, in the ratio of one part dried plant material to six parts of water. A spray-drying method was used to concentrate the extract to dryness, in which the tower inlet and outlet temperatures were set at 185 and $107^{\circ} \mathrm{C}$, respectively. The spray-dried extract was kept at $4-8^{\circ} \mathrm{C}$, in a dessicator, away from light and only sufficient amount was taken each time for use.

2.2. Animal Care and Treatments. Wistar rats were continuously exposed to dihydrotestosterone (DHT) from puberty to adult age to develop PCOS characteristics as previously described [25]. After $7 \mathrm{wk}$ of DHT exposure, rats were randomized into two groups, PCOS-LP $(n=11)$ and PCOScontrol $(n=11)$.

The PCOS-LP group received extracted LP orally $(50 \mathrm{mg} / \mathrm{kg}$ of body weight dissolved in $1 \mathrm{~mL}$ of distilled water) daily during 4-5 weeks; the PCOS-control group received $1 \mathrm{~mL}$ of distilled water. The dose of LPva was based on previous work by our group [26] and we decided to use the maximum dose applied which influenced several biochemical and physiological variables in these studies. At the end of the experiment, mesenteric adipose tissue was harvested and kept in RNA later stabilization solution (Ambion, Austin, TX, USA) for $24 \mathrm{~h}$ at $4^{\circ} \mathrm{C}$ and then stored at $-80^{\circ} \mathrm{C}$ for $\mathrm{mRNA}$ analyses. The study was approved by the Animal Ethics Committee of the University of Gothenburg.

2.3. Euglycemic Hyperinsulinemic Clamp. At $14-15$ weeks of age (i.e., after 4-5 weeks of treatment, 10-11 weeks after pellet implantation), rats were subjected to a euglycemichyperinsulinemic clamp. The rats were anesthetized with thiobutabarbital sodium (130 mg/kg i.p.; Inactin, Sigma, St. Louis, MO, USA). Catheters were inserted into the left carotid artery and the right jugular vein. A tracheotomy was performed to facilitate respiration. Body temperature was maintained at $37^{\circ} \mathrm{C}$ with a heating pad. Insulin $(100 \mathrm{IU} / \mathrm{mL}$; Actrapid, Novo Nordisk, Bagsvaerd, Denmark) together with $0.2 \mathrm{~mL}$ of albumin and $10 \mathrm{~mL}$ of physiological saline was infused at 24,16 , and $12 \mathrm{mU} / \mathrm{min} / \mathrm{kg}$ for 1,2 , and $3 \mathrm{~min}$, respectively, followed by $8 \mathrm{mU} / \mathrm{min} / \mathrm{kg}$ for the rest of the clamp. Simultaneously, a $20 \%$ glucose solution in physiological saline was administered to maintain blood glucose levels at a euglycemic level $(6.0 \mathrm{mM})$. The glucose infusion rate was guided by measuring glucose concentration every $5 \mathrm{~min}$ with a B-glucose analyser (Hemocue, Dronfield, Derbyshire, UK). The mean glucose infusion rate, normalized to body weight, was calculated at steady state (after approximately 50-70 min) as an index of insulin sensitivity. Blood samples were taken at the end of the clamp to determine insulin concentrations. Due to failure of the clamp, three PCOS control rat and one PCOS LP rats were excluded from the analyses of $\mathrm{mRNA}$ and protein expressions.

2.4. Cell Culture and Treatment. Mouse 3T3-L1 (ATCC CL173) preadipocyte cells were maintained in DMEM containing $10 \%$ calf serum. For the differentiation, postconfluent 3T3-L1 preadipocytes (referred to as day 0 ) were treated with DMEM containing $10 \%$ FBS, $10 \mu \mathrm{g} / \mathrm{mL}$ insulin, $0.5 \mathrm{mM} \mathrm{3-}$ isobutyl-1-methylxanthine, and $1 \mu \mathrm{M}$ dexamethasone for 2 days and were then treated for 2 days with DMEM containing $10 \mu \mathrm{g} / \mathrm{mL}$ insulin and 10\% FBS. Thereafter, cells were maintained and refed every 2 days with DMEM containing $10 \%$ FBS. With this protocol, $>80 \%$ adipocyte differentiation was achieved. 3T3-L1 cells were treated with final concentrations of $100 \mu \mathrm{g} / \mathrm{mL}$ of LP or $10 \mu \mathrm{M}$ of rosiglitazone, a type of TZD (Sigma-Aldrich), along with the differentiation medium containing INS-DEX-IBMX since day 0. Control cells were treated with the same volume of DMSO. At day 9, adipocytes were incubated in low-glucose DMEM (GIBCO$\mathrm{BRL}$ ) containing $2 \%(\mathrm{wt} / \mathrm{vol})$ fatty acid-free BSA and were serum starved for $24 \mathrm{~h}$. At day 10, the RNA and protein were extracted for further analysis.

2.5. Analysis of $m R N A$ by Quantitative Real-Time PCR. Total RNA was isolated from adipose tissues cells using RNeasy Kit (Qiagen Inc. Germany). The RNA concentration was quantitated by measuring the absorbency at 260 and 
$280 \mathrm{~nm}$. First-strand cDNA was synthesized from $2 \mu \mathrm{g}$ of total RNA extracted using TaqMan Reverse Transcription Reagent (Applied Biosystems, Foster City, CA, USA). The resulting cDNA solution was diluted 45 times and stored at $-20^{\circ} \mathrm{C}$ for later use. In the second step, $100 \mathrm{ng}$ cDNA was used for PCR using TaqMan Universal PCR Master Mix (Applied Biosystems, Branchburg, NJ, USA) in a 96-well plate according to the manufacturer's instructions. We used TaqMan specific primers for PPARgamma, and $\beta$-actin in our experiments was purchased from Applied Biosystems (Warrington, UK). The real-time quantitative PCR and analysis were carried out using the ABI Prism 7300 Real-time PCR System (Foster City, CA, USA). The relative quantification was determined by the standard curve method for both target and endogenous reference. Real-time PCR analyses were run in triplicate and expression was normalized to the levels of the housekeeping control $\beta$-actin.

\subsection{Protein Expression Levels}

2.6.1. Preparation of Adipose Tissue Extract. Frozen tissues were homogenized in a buffer containing $150 \mathrm{mmol} / \mathrm{L} \mathrm{NaCl}$, $10 \mathrm{mmol} / \mathrm{L}$ Tris, $\mathrm{pH} 7.4,1 \mathrm{mmol} / \mathrm{L}$ (ethylenebis (oxyethylenenitrilo)) tetraacetic acid, $1 \mathrm{mmol} / \mathrm{L}$ EDTA, $1 \%$ Triton-X 100, 0.5\% Igepal CA-630, $1 \mu \mathrm{mol} / \mathrm{L}$ phenylmethylsulphonyl fluoride, $1 \mu \mathrm{mol} / \mathrm{L}$ pepstatin, 50 trypsin inhibitory milliunits of aprotinin, $10 \mu \mathrm{mol} / \mathrm{L}$ leupeptin, and $2 \mathrm{mmol} / \mathrm{L}$ sodium vanadate). Homogenates were centrifuged for $10 \mathrm{~min}$ at 9,000 g to remove any debris and insoluble material and then analysed for protein content using BCA protein assay (Pierce Chemical Co., Rockland, IL, USA).

2.6.2. Preparation of Whole Cell Extracts. Monolayers of 3T3L1 adipocytes were rinsed with phosphate-buffered saline and then harvested in a nondenaturing buffer containing $150 \mathrm{mmol} / \mathrm{L} \mathrm{NaCl}, 10 \mathrm{mmol} / \mathrm{L}$ Tris, $\mathrm{pH} 7.4,1 \mathrm{mmol} / \mathrm{L}$ (ethylenebis (oxyethylenenitrilo)) tetraacetic acid, $1 \mathrm{mmol} / \mathrm{L}$ EDTA, 1\% Triton-X 100, 0.5\% IGEPAL CA-630 (Nonidet P40), $1 \mu \mathrm{mol} / \mathrm{L}$ phenylmethylsulfonyl fluoride, $1 \mu \mathrm{mol} / \mathrm{L}$ pepstatin, 50 trypsin inhibitory milliunits of aprotinin, $10 \mu \mathrm{mol} / \mathrm{L}$ leupeptin, and $2 \mathrm{mmol} / \mathrm{L}$ sodium vanadate. Samples were extracted on ice for $30 \mathrm{~min}$ and centrifuged at $13,000 \mathrm{~g}$ at $4^{\circ} \mathrm{C}$ for $10 \mathrm{~min}$. Supernatants containing whole cell extracts were analysed for protein concentration using BCA protein assay (Pierce Chemical Co., Rockland, IL, USA) according to the manufacturer's instructions.

2.6.3. Gel Electrophoresis and Western Blot Analysis. Cell lysates were prepared in buffer containing a 1:100 dilution of protease inhibitor cocktail III (Calbiochem, La Jolla, CA, USA), electrophoresed on SDS-polyacrylamide gels. The proteins were transferred to polyvinylidene difluoride membrane by electroblotting and blocked for $1 \mathrm{~h}$ in $5 \%$ nonfat dry milk. The membrane then incubated for $1 \mathrm{~h}$ with polyclonal antibodies against PPARgamma (Abcam, Cambridge, UK) and later probed with horseradish peroxidase-conjugated secondary antibodies (Abcam). Finally, the membrane was washed and developed using SuperSignal West Pico chemiluminescence reagent (Pierce Chemical Co. Rockford, IL, USA). Densitometry was performed using Bio-Rad Laboratories, Inc. molecular analyst software (Hercules, CA, USA).

2.7. Uptake of 2-Deoxyglucose. Uptake of 2-deoxylglucose by the 3T3-L1 adipocytes was measured as previously described [27]. To induce insulin resistance, 3T3-L1 adipocytes were incubated in low glucose DMEM containing 10-8 $\mathrm{M}$ insulin for the last $16 \mathrm{~h}$ of serum starvation. Cells were treated with or without $100 \mu \mathrm{g} / \mathrm{mL}$ of LP or $10 \mu \mathrm{M}$ of rosiglitazone throughout the differentiation at $37^{\circ} \mathrm{C}$ and then stimulated with or without $100 \mathrm{nM}$ insulin for the final $1 \mathrm{~h}$ at $37^{\circ} \mathrm{C}$. The potency of LP for PPARgamma was estimated according to EC50 value of $96.78 \mu \mathrm{g} / \mathrm{mL}$ (results not shown) Ten $\mu \mathrm{M}$ of rosiglitazone was used in various experiments [28, 29]. Glucose uptake was initiated by the addition of 2-deoxy$\mathrm{d}-[3 \mathrm{H}]$ glucose at a final concentration of $3 \mu \mathrm{mol} / \mathrm{L}$ for $10 \mathrm{~min}$ in HEPES buffer saline $(140 \mathrm{mM} \mathrm{NaCl}, 5 \mathrm{mM} \mathrm{KCl}$, $2.5 \mathrm{mM} \mathrm{MgCl}_{2}, 1 \mathrm{mM} \mathrm{CaCl}_{2}, 20 \mathrm{mM}$ HEPES, and $\left.\mathrm{pH} 7.4\right)$. The reaction was terminated by separating cells from the HEPES buffer saline and 2-deoxy-d-[3H] glucose. After three washes in ice-cold PBS, the cells were extracted with $0.1 \%$ SDS and subjected to scintillation counting for $3 \mathrm{H}$ radioactivity. The protein concentration was determined with a BCA assay kit (Pierce, Rockford, IL, USA), and the radioactivities were normalized by determining each total protein concentration.

2.8. Statistical Analysis. Each experiment was performed in triplicate. All results were expressed as mean \pm SEM Comparisons were analyzed by the Mann-Whitney $U$ test and 0ne-way ANOVA followed by Newman-Keuls multiple comparison test. Differences were considered statistically significantly if the $P$ value is less than 0.05 .

\section{Results}

3.1. Insulin Sensitivity. LP-increases insulin sensitivity. The glucose infusion rate, determined by a euglycemichyperinsulinemic clamp, was 35\% higher in LP treated rats than in controls, indicating improved insulin sensitivity (Figure 1(a)).

3.2. mRNA Levels of the PPARgamma Gene. To determine the PPARgamma mRNA levels in 3T3-L1 and rat adipose tissues, real-time RT-PCR method was used. LP treatment upregulated the PPARgamma expression in mesenteric adipose tissue in DHT-induced PCOS rats (Figure 1(b)). The expression of PPARgamma in 3T3-L1 was markedly increased by TZD treatment, as expected. LP equally up-regulated PPARgamma as TZD (Figure 2(a)).

3.3. Protein Expression Levels of PPARgamma. To determine the translational level of PPARgamma mRNA into protein, the protein levels were assessed by Western blot analysis. The 


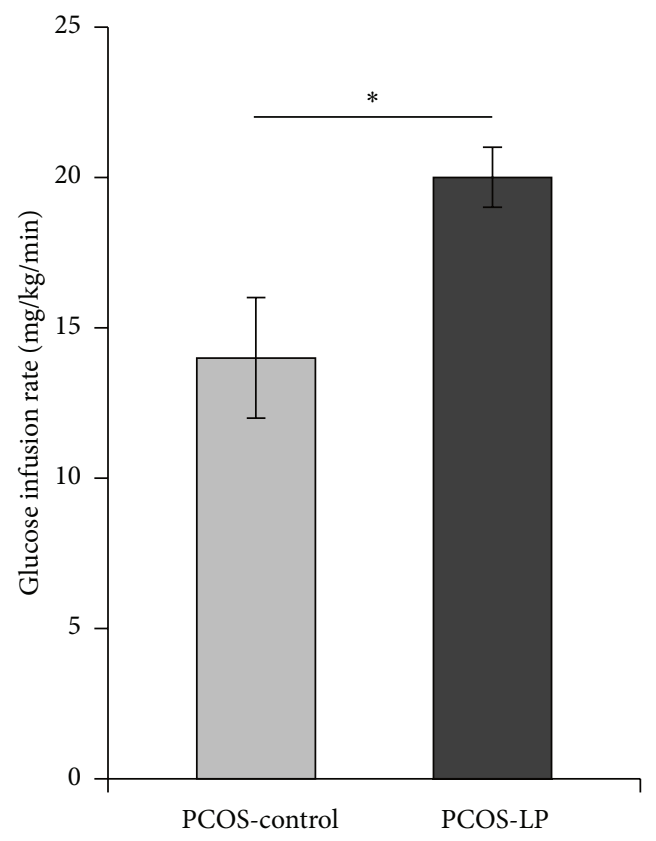

(a)

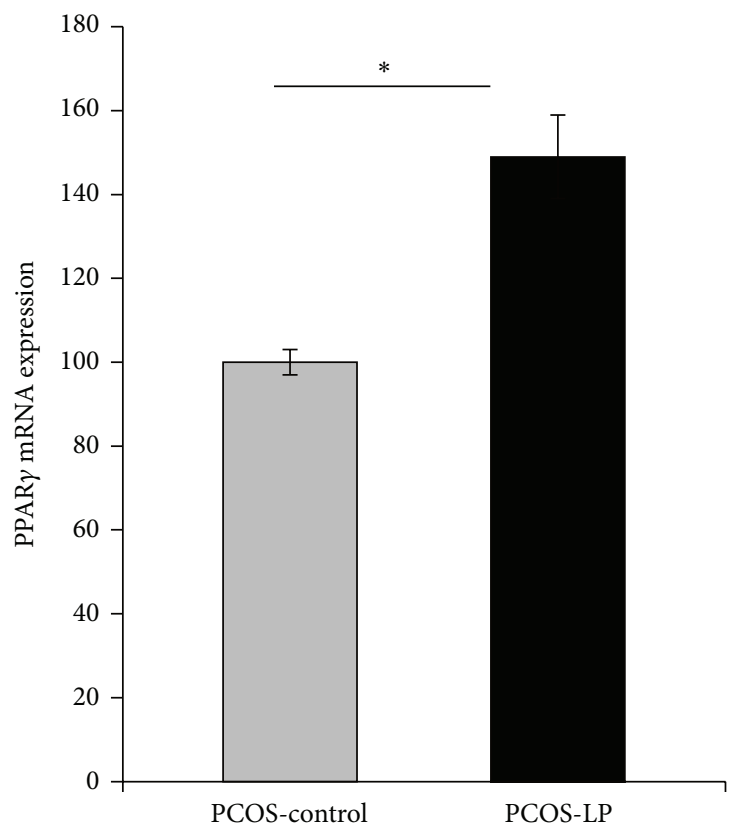

(c)

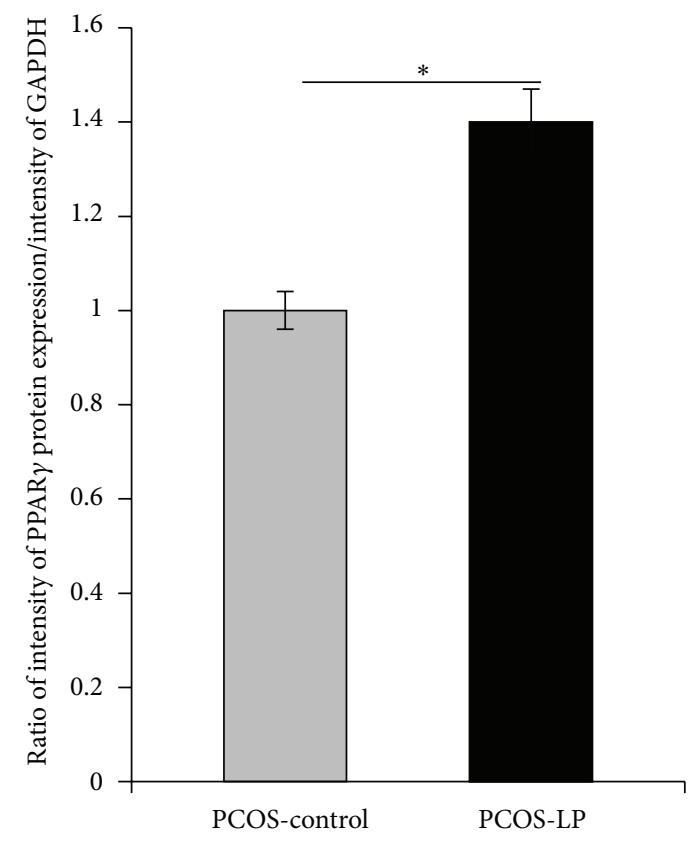

(b)

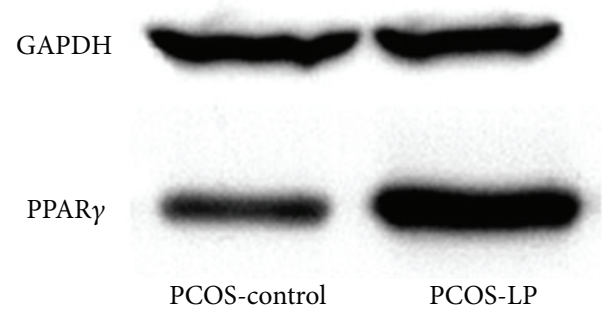

(d)

FIGURE 1: (a) Glucose infusion rate, at steady state, required to maintain euglycemia during euglycemic-hyperinsulinemic clamp in PCOS LPva rats and PCOS controls. Values are mean \pm SEM, PCOS LP versus PCOS-control, ${ }^{*} P<0.05$ (the Mann-Whitney $U$ test). (b) Quantitative blot of PPARgamma protein in PCOS rat adipose tissues. (c) Relative PPARgamma mRNA expression in the adipose tissue of PCOS control $(n=8)$ versus PCOS LP $(n=10)$. The mRNA was corrected by $\beta$-actin. The level of the expression in the control group was arbitrarily set at $100 \%$. (d) Representative Western blot of PPARgamma in PCOS rat adipose tissues. Western blots of total protein were probed with anti-PPARgamma antibodies and then reprobed with anti-GAPDH to confirm equal loading. Densitometric analyses presented as the relative ratio of PPARgamma to GAPDH. The results represent mean \pm S.E.M. from 3 independent experiments. ${ }^{*} P<0.05$ as determined by the Mann-Whitney $U$ test. 


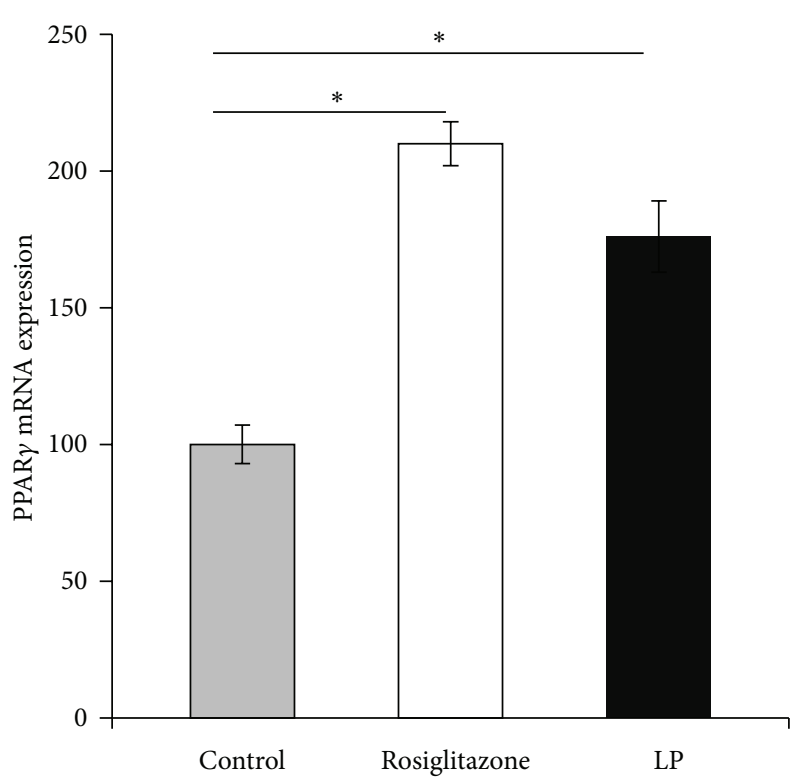

(a)

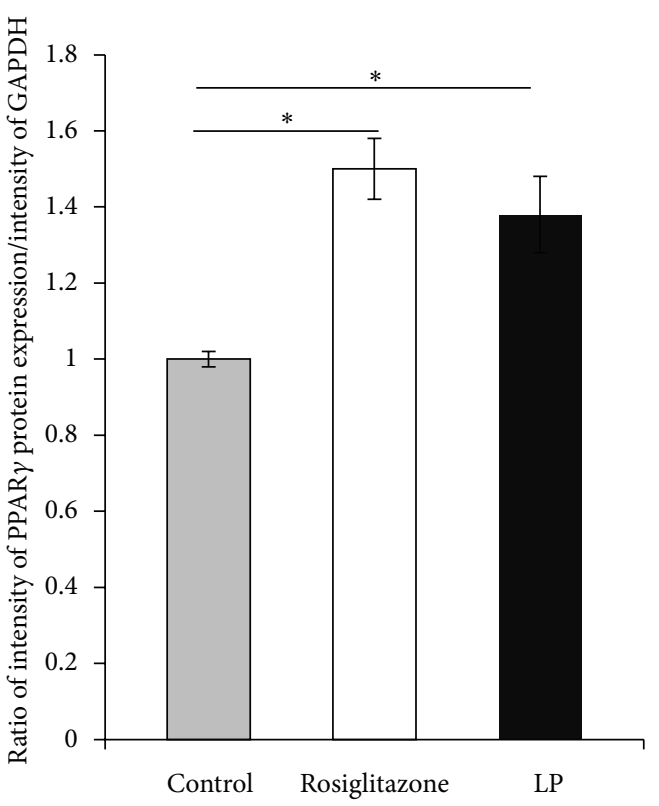

(b)

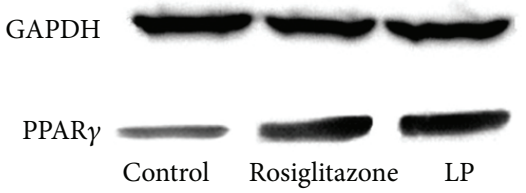

(c)

FIGURE 2: Effect of LP mRNA and protein expressions on3T3-L1 adipocytes. (a) Relative PPARgamma mRNA expression in the 3T3-L1 $(n=10) .{ }^{*} P<0.05$. The mRNA was corrected by $\beta$-actin. The level of the expression in the control group was arbitrarily set at $100 \%$. (b) Quantitative blot of PPARgamma protein in 3T3-L1 adipocytes. (c) Representative Western blot of PPARgamma protein in 3T3-L1. Western blots of total protein were probed with anti-PPARgamma antibodies and then reprobed with anti-GAPDH to confirm equal loading. Densitometric analyses presented as the relative ratio of PPARgamma to GAPDH. The results represent mean \pm SEM from 3 independent experiments. ${ }^{*} P<0.05$ as determined by the Mann-Whitney $U$ test.

mesenteric PPARgamma protein expression was increased after 4-5 weeks of LP treatment in DHT-induced compared with control PCOS rats (Figures $1(\mathrm{c})$ and $1(\mathrm{~d})$ ). TZD and LP equally increased PPARgamma protein levels in the 3T3-L1 adipocytes (Figures 2(b) and 2(c)).

3.4. Effects of Glucose Uptake by LP in 3T3-L1 Adipocytes. Stimulation of cells with $100 \mathrm{nM}$ insulin increased glucose uptake by threefold in the insulin-resistant cells (Figure 3). Incubation of 3T3-L1 adipocytes with rosiglitazone as a positive control for $24 \mathrm{~h}$ increased the insulin-stimulated glucose transport activity compared with the absence of rosiglitazone in the control cells. Treatment of LP in basal glucose uptake is comparable to rosiglitazone. LP treatment showed enhancement of insulin-stimulated glucose uptake but not as high as rosiglitazone. However, the glucose uptake in cotreatment was less than that of rosiglitazone monotherapy. It is supposed that the effect of rosiglitazone on glucose uptake was inhibited by LP, and this seems to be related to the effect of PPARgamma transcriptional activity.

\section{Discussion}

Numerous scientific researches on LP are being carried out, especially for the identification of bioactive phytochemicals that contribute to the pharmacological properties. Most of the phytochemicals that have been identified from the LP extract are phenolic compounds, including phenolic acids and flavonoids as reported [4, 5, 30]. Additionally, in the recent first comprehensive phytochemical study on LP, 19 compounds were isolated from LP [31]. However, isolation of bioactive compounds responsible for the observed activities is necessary for further confirmation.

DHT-induced rat PCOS model exhibits both ovarian and metabolic disturbances similar to human PCOS [25]. One of the characteristics is the presence of insulin resistance. We observed that in the DHT-induced PCOS rats, LP treatment resulted in improvement of glucose homeostasis measured using euglycemic-hyperinsulinemic clamp. Meanwhile the 3T3-L1 has been shown to be a useful model when investigating the mechanism of expression of PPARgamma, provided it can differentiate from preadipocytes to adipocytes under 


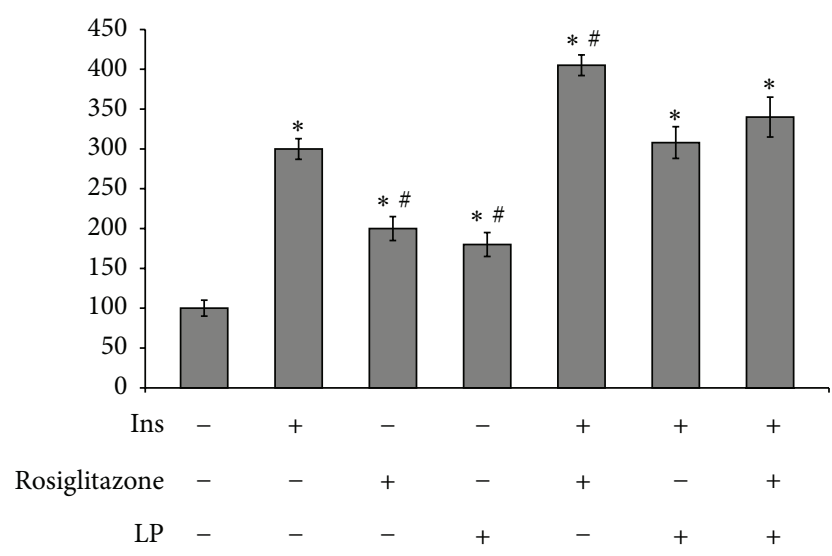

FIGURE 3: Effects of LP on glucose uptake. Glucose uptake activity in 3T3-L1 adipocytes under insulin-resistant condition in the presence and absence of insulin. The glucose uptake value of untreated cells was set 100 , and the others were relative values. Data represented the mean $\pm \operatorname{SEM}(n=5) .{ }^{*} P<0.05$ versus control, ${ }^{\#} P<0.05$ versus insulin only.

certain stimulating conditions [27]. Therefore, in this current study, we determined the expression and protein levels of PPARgamma in the mesenteric adipose tissues and 3T3L1 cell line in order to further understand the mechanisms involved in the effect of LP on PPARgamma gene and protein expression.

As shown in the present study, there were higher gene and protein expressions of PPARgamma in the adipose tissues obtained from the DHT-induced PCOS rats treated with LP. Similarly, when insulin-resistant 3T3-L1 cells were treated with LP extract, there was increased insulin-stimulated glucose uptake at the cellular level; both expression and protein levels of PPARgamma were found to be significantly higher compared to the untreated cells.

Thiazolidinediones (TZD) represent a class of oral hypoglycemic agents that have been shown to improve insulin action and reverse some of the metabolic processes responsible for the development of insulin resistance and, finally, type 2 diabetes in predisposed subjects $[32,33]$. As expected, TZD increased significantly compared to control cells. At cellular level, the insulin sensitizing effects of TZDs are mediated through the peroxisome proliferator-activated receptor $\gamma$ $(\operatorname{PPAR} \gamma)[31]$ which is highly abundant in adipose tissue and to a lesser extent in skeletal muscle and liver $[34,35]$. A representative of TZD, rosiglitazone, is a potent agonist of PPAR $\gamma$ and improves the differentiation of 3T3-L1 cells into adipocytes $[12,13]$. Furthermore, adipocyte differentiation leads to the enhanced expression of adipocyte-specific genes, such as GLUT4 and insulin receptor substrate-1 (IRS-1), which are important components of the insulin receptor signal transduction pathway $[36,37]$.

PPARgamma activation through binding of the synthetic TZDs in type 2 diabetic patients results in a marked improvement in whole-body insulin sensitivity, leading to reduced insulin and glucose plasma levels. At the cellular level, PPARgamma activation has been shown to affect the insulin signaling cascade, through direct modulatory effects on the expression and/or phosphorylation of specific signaling molecules [38]. It is proven that dietary components can bind and activate PPARgamma [17]. However the specificity of the dietary compounds to act as ligands for PPARgamma is still unclear. A metabolic of the parent compound, not the parent compound itself, might be mediating the responces through interactions with PPARgamma.

Taken together, our studies to date suggest that LP, or more specifically, the compounds present in the aqueous extract, at least partially acts via the PPARgamma pathway, resulting in upregulated PPARgamma. It is not only at the transcriptional level but also at translational level of this nuclear receptor in the adipose tissues, leading to improvement in insulin sensitivity and hence increased uptake of glucose by fat cells. Thus, it may improve the understanding of mechanism of action of LP on insulin sensitivity.

\section{Conflict of Interests}

The authors declare no conflict of interests.

\section{Acknowledgments}

The authors wish to thank the Director General of Health Malaysia for his permission to publish this paper. They also wish to thank Professor M.M. Yusoff (Universiti Malaysia Pahang) for providing them with the L. pumila var. alata standardized water extract and the Director General of Forest Research Institute Malaysia (FRIM) for providing them with the voucher specimen. This work was supported by grants from the Ministry of Science, Technology, and Innovation, Malaysia (Grant no. 06-05-IFN-BPH004), the Swedish Research Council, and the Swedish Diabetes Association.

\section{References}

[1] I. H. Burkill, Dictionary of the Economic Products of the Malay Peninsula, vol. 2, Crown Agents for the Colonies, London, UK, 1935.

[2] B. Sunarno, "Revision of the genus Labisia (Myrsinaceae)," Blumea, vol. 50, no. 3, pp. 579-597, 2005.

[3] M. Zakaria and M. A. Mohd, Traditional Malay Medicinal Plants, Penerbit Fajar Bakti Sdn Bhd, Kuala Lumpur, Malaysia, 1994.

[4] M. Norhaiza, M. Maziah, and M. Hakiman, "Antioxidative properties of leaf extracts of a popular Malaysian herb, Labisia pumila," Journal of Medicinal Plant Research, vol. 3, no. 4, pp. 217-223, 2009.

[5] E. Karimi, H. Z. E. Jaafar, and S. Ahmad, "Phytochemical analysis and antimicrobial activities of methanolic extracts of leaf, stem and root from different varieties of labisa pumila benth," Molecules, vol. 16, no. 6, pp. 4438-4450, 2011.

[6] C. Gayet, V. Leray, M. Saito, B. Siliart, and P. Nguyen, "The effects of obesity-associated insulin resistance on mRNA expression of peroxisome proliferator-activated receptor- $\gamma$ target genes, in dogs," British Journal of Nutrition, vol. 98, no. 3, pp. 497-503, 2007.

[7] M. H. Fonseca-Alaniz, J. Takada, M. I. C. Alonso-Vale, and F. B. Lima, "Adipose tissue as an endocrine organ: from theory 
to practice," Jornal de Pediatria, vol. 83, no. 5, supplement, pp. S192-S203, 2007.

[8] A. Guilherme, J. V. Virbasius, V. Puri, and M. P. Czech, "Adipocyte dysfunctions linking obesity to insulin resistance and type 2 diabetes," Nature Reviews Molecular Cell Biology, vol. 9, no. 5, pp. 367-377, 2008.

[9] S. E. Kahn, R. L. Hull, and K. M. Utzschneider, "Mechanisms linking obesity to insulin resistance and type 2 diabetes," Nature, vol. 444, no. 7121, pp. 840-846, 2006.

[10] M. E. Greene, B. Blumberg, O. W. McBride et al., "isolation of the human peroxisome proliferator activated receptor $\gamma \mathrm{cDNA}$ : expression in hematopoietic cells and chromosomal mapping," Gene Expression, vol. 4, no. 4-5, pp. 281-299, 1995.

[11] O. Braissant, F. Foufelle, C. Scotto, M. Dauça, and W. Wahli, "Differential expression of peroxisome proliferator-activated receptors (PPARs): tissue distribution of PPAR $-\alpha,-\beta$, and $-\gamma$ in the adult rat," Endocrinology, vol. 137, no. 1, pp. 354-366, 1996.

[12] S. M. Rangwala and M. A. Lazar, "Peroxisome proliferatoractivated receptor $\gamma$ in diabetes and metabolism," Trends in Pharmacological Sciences, vol. 25, no. 6, pp. 331-336, 2004.

[13] J. Velebit, P. B. Kovacic, M. Prebil et al., "Rosiglitazone modulates insulin-induced plasma membrane area changes in single 3T3-L1 adipocytes," Journal of Membrane Biology, vol. 223, no. 3, pp. 141-149, 2008.

[14] T. P. Combs, J. A. Wagner, J. Berger et al., "Induction of adipocyte complement-related protein of 30 kilodaltons by PPAR $\gamma$ agonists: a potential mechanism of insulin sensitization," Endocrinology, vol. 143, no. 3, pp. 998-1007, 2002.

[15] N. Maeda, M. Takahashi, T. Funahashi et al., "PPAR $\gamma$ ligands increase expression and plasma concentrations of adiponectin, an adipose-derived protein," Diabetes, vol. 50, no. 9, pp. $2094-$ 2099, 2001.

[16] J. P. Berger, "Role of PPAR $\gamma$, transcriptional cofactors, and adiponectin in the regulation of nutrient metabolism, adipogenesis and insulin action: view from the chair," International Journal of Obesity, vol. 29, no. 1, supplement, pp. S3-S4, 2005.

[17] M. Penumetcha and N. Santanam, "Nutraceuticals as ligands of PPARy," PPAR Research, vol. 2012, Article ID 858352, 7 pages, 2012.

[18] D. A. Ehrmann, "Polycystic ovary syndrome," New England Journal of Medicine, vol. 352, no. 12, pp. 1223-1277, 2005.

[19] A. H. Balen, G. S. Conway, G. Kaltsas et al., "Polycystic ovary syndrome: the spectrum of the disorder in 1741 patients," Human Reproduction, vol. 10, no. 8, pp. 2107-2111, 1995.

[20] R. Azziz, "PCOS: a diagnostic challenge," Reproductive BioMedicine Online, vol. 8, no. 6, pp. 644-648, 2004.

[21] T. M. Barber, M. I. McCarthy, J. A. H. Wass, and S. Franks, "Obesity and polycystic ovary syndrome," Clinical Endocrinology, vol. 65, no. 2, pp. 137-145, 2006.

[22] A. L. Hirschberg, "Polycystic ovary syndrome, obesity and reproductive implications," Women's Health, vol. 5, no. 5, pp. 529-542, 2009.

[23] L. Mannerås, M. Fazliana, W. M. Wan Nazaimoon et al., "Beneficial metabolic effects of the Malaysian herb Labisia pumila var. alata in a rat model of polycystic ovary syndrome," Journal of Ethnopharmacology, vol. 127, no. 2, pp. 346-351, 2010.

[24] M. M. Yusoff and W. M. Wan Nazaimoon, "Process for preparation of Labisia pumila extract," United States Patent US7879368B2, 2011.

[25] L. Mannerås, S. Cajander, A. Holmäng et al., "A new rat model exhibiting both ovarian and metabolic characteristics of polycystic ovary syndrome," Endocrinology, vol. 148, no. 8, pp. 3781-3791, 2007.

[26] M. Fazliana, W. M. Wan Nazaimoon, H. F. Gu, and C.-G. Östenson, "Labisia pumila extract regulates body weight and adipokines in ovariectomized rats," Maturitas, vol. 62, no. 1, pp. 91-97, 2009.

[27] V. P. Knutson and Y. Balba, "3T3-L1 adipocytes as a cell culture model of insulin resistance," In Vitro Cellular and Developmental Biology, vol. 33, no. 2, pp. 77-81, 1997.

[28] L. Martinez, M. Berenguer, M. C. Bruce, Y. Le MarchandBrustel, and R. Govers, "Rosiglitazone increases cell surface GLUT4 levels in 3T3-L1 adipocytes through an enhancement of endosomal recycling," Biochemical Pharmacology, vol. 79, no. 9, pp. 1300-1309, 2010.

[29] K. W. Lee, Y. H. Ku, M. Kim, B. Y. Ahn, S. S. Chung, and K. S. Park, "Effects of sulfonylureas on peroxisome proliferatoractivated receptor $\gamma$ activity and on glucose uptake by thiazolidinediones," Diabetes \& Metabolism Journal, vol. 35, no. 4, pp. 340-347, 2011.

[30] L. S. Chua, S. Y. Lee, N. Abdullah, and M. R. Sarmidi, "Review on Labisia pumila (Kacip Fatimah): bioactive phytochemicals and skin collagen synthesis promoting herb," Fitoterapia, vol. 83, no. 8, pp. 1322-1335, 2012.

[31] N. A. Al-Mekhlafi, K. Shaari, F. Abas et al., "Alkenylresorcinols and cytotoxic activity of the constituents isolated from Labisia pumila," Phytochemistry, vol. 80, pp. 42-49, 2012.

[32] V. Bhatia and P. Viswanathan, "Insulin resistance and PPAR insulin sensitizers," Current Opinion in Investigational Drugs, vol. 7, no. 10, pp. 891-897, 2006.

[33] S. Mudaliar and R. R. Henry, "New oral therapies for type 2 diabetes mellitus: the glitazones or insulin sensitizers," Annual Review of Medicine, vol. 52, pp. 239-257, 2001.

[34] J. Auwerx, "PPAR $\gamma$, the ultimate thrifty gene," Diabetologia, vol. 42, no. 9, pp. 1033-1049, 1999.

[35] J. M. Olefsky, “Treatment of insulin resistance with peroxisome proliferator-activated receptor $\gamma$ agonists," Journal of Clinical Investigation, vol. 106, no. 4, pp. 467-472, 2000.

[36] J. M. Ntambi and K. Young-Cheul, "Adipocyte differentiation and gene expression," Journal of Nutrition, vol. 130, no. 12, pp. 3122S-3126S, 2000.

[37] M. F. White and C. R. Kahn, "The insulin signaling system," Journal of Biological Chemistry, vol. 269, no. 1, pp. 1-4, 1994.

[38] F. Giorgino, A. Leonardini, L. Laviola, S. Perrini, and A. Natalicchio, "Cross-talk between PPAR $\gamma$ and insulin signaling and modulation of insulin sensitivity," PPAR Research, vol. 2009, Article ID 818945, 12 pages, 2009. 

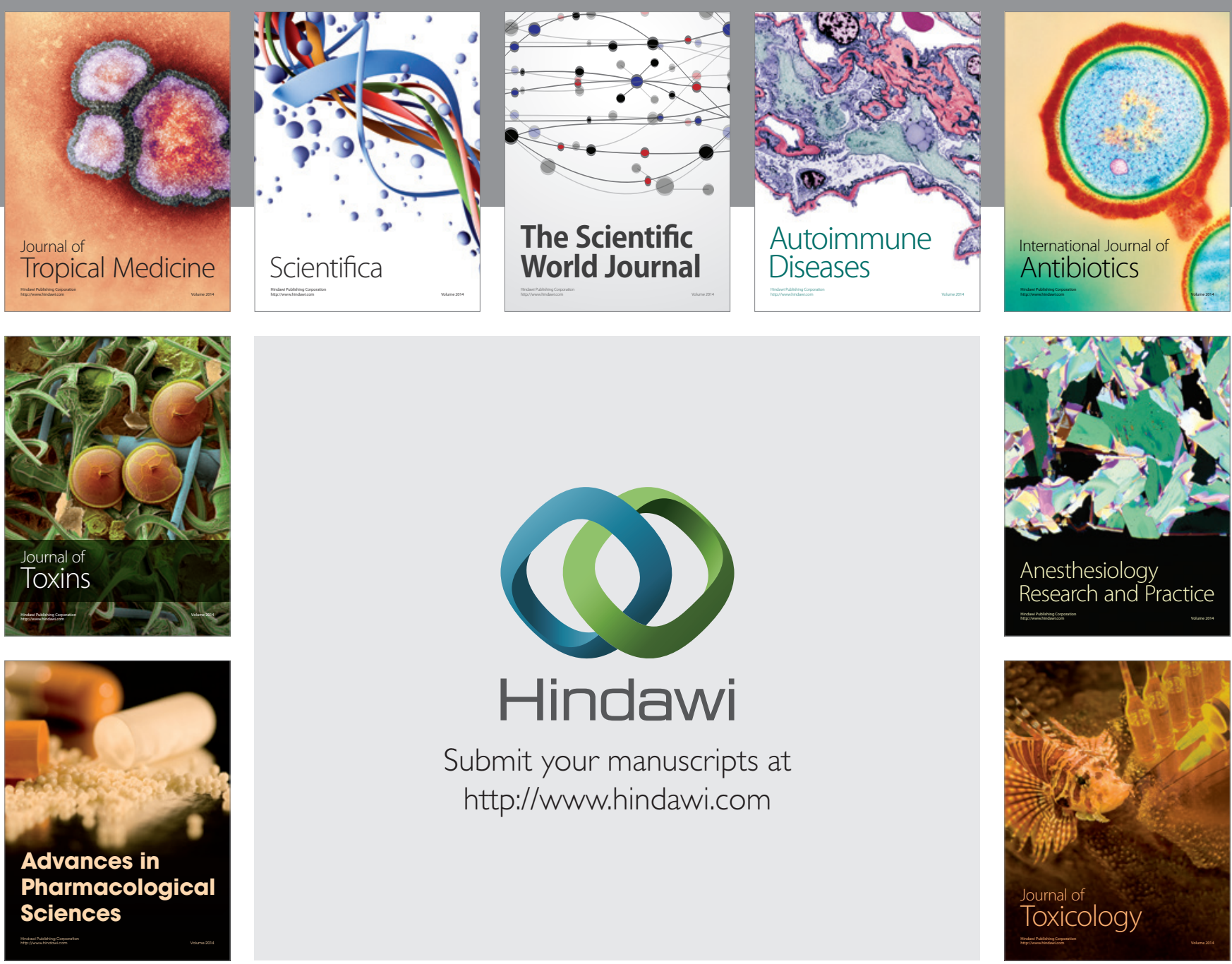

\section{Hindawi}

Submit your manuscripts at

http://www.hindawi.com
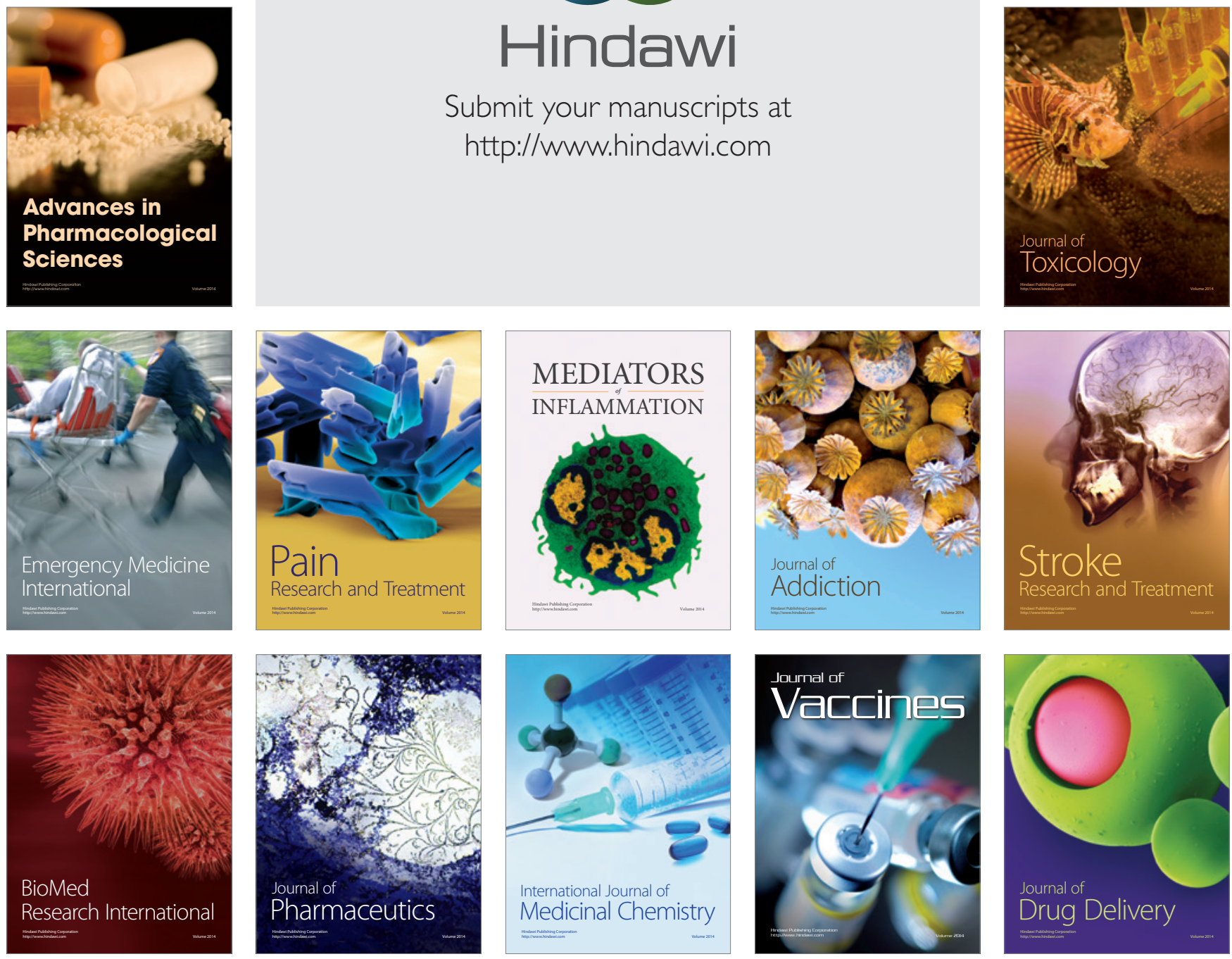